http://jmscr.igmpublication.org/home/

ISSN (e)-2347-176x ISSN (p) 2455-0450

crossref DOI: https://dx.doi.org/10.18535/jmscr/v7i10.155

Journal Of Medical Science And Clinical Research

IGM Publication

An Official Publication of IGM Publication

\title{
Case Report: Snake Bite (Russell's viper) induced Acute Myocardial Infarction
}

\author{
Authors \\ Dr Ganesh.K ${ }^{1}$, Prof. Dr S.Balasubramaniyan.M.D², Dr N. Paari M.D. ${ }^{3}$ \\ ${ }^{1}$ Post Graduate, Department of General Medicine, Rajah Muthiah Medical College \& Hospital, \\ Annamalai University, Chidambaram, India - 608002 \\ ${ }^{2}$ Professor, Department of General Medicine, Rajah Muthiah Medical College \& Hospital, \\ Annamalai University, Chidambaram, India - 608002 \\ ${ }^{3}$ AssistantProfessor, Department of General Medicine, Rajah Muthiah Medical College \& Hospital, \\ Annamalai University, Chidambaram, India - 608002
}

\section{Introduction}

Snake bites are well known emergencies and a cause of hospital admission in many countries. India is one of the world's most affected country due to its high population density, widespread agricultural activities, presence of numerous venomous snakes and lake of necessary community awareness to address the problem. In India alone it has been estimated that as many as 2.8 million people are bitten by snakes and 46,900 people die from snake bite every year. ${ }^{10}$

Out of 236 species of snakes in India, 13 species are poisonous and of these four, namely common cobra (Naja naja), Russell's viper (Dabiola russelii), saw scaled viper (Echis cartinatus) and common krait (Bungarus caeruleus) are highly venomous and believed to be responsible for most of the poisonous bites in India. ${ }^{11}$

Viper toxins are haemotoxic. Cobra and krait are neurotoxic. Russell's viper can also manifest with neurotoxic symptoms. Cardiac manifestations are rare in viper bite. Acute myocardial infarction caused by viper bite has been reported rarely. Here we report a case of ST elevation myocardial infarction following Russell's viper snake bite. This case highlights the cardiovascular complications following viper bite.

\section{Case Report}

A 49 years old male presented to the casualty with alleged history of snake bite over left side chest wall three hour after the incidence. Patient brought the dead snake which was identified as Russell's viper. He complained of pain and swelling over the bite site. He had no other comorbidities. There was no significant family history.

On examination he was conscious, oriented, PR: 80/min, BP: 130/90mmHg, Respiratory rate $18 / \mathrm{min}, \mathrm{SpO}_{2} 99 \%$ in room air. Fang mark was present over the bite site with cellulitis. There was no neurological or bleeding manifestations. Systemic examinations were normal. His 20 minutes whole blood clotting time (WBCT) was prolonged, bleeding time was 3 minutes 24 seconds, clotting time was 5 minutes 11 seconds. ECG showed heart rate $\approx 80 / \mathrm{min}$, normal axis, normal sinus rhythm, no significant ST-T 
changes. Urine examination and other Blood Biochemistry were within normal limit. Polyvalent anti-snake venom was administered immediately. Repeat WBCT after 6 hours was less than 20 minutes.

Fig: 1 ECG at the time of admission

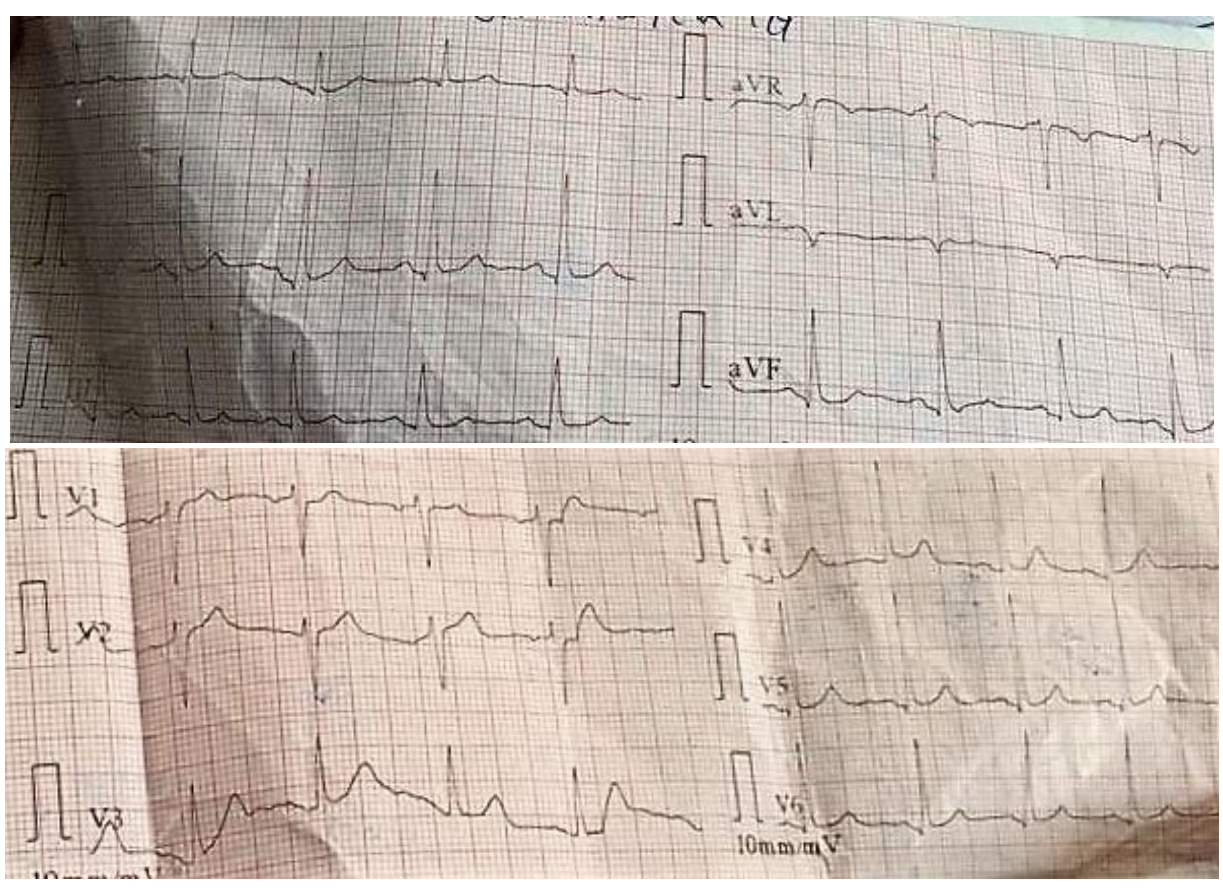

20 hours after bite patient developed retrosternal chest pain, giddiness and palpitation. His pulse rate was 126/min, irregularly irregular, BP: 110/70mmHg, CVS: S1, S2 heard, S1 variable, other system examination were normal. ECG showed HR $\approx 110 /$ min, irregular rhythm (atrial fibrillation with rapid ventricular response), normal axis, ST elevation in lead I and aVL with reciprocal changes. Cardiac troponin $\mathrm{T}$ was positive. Patient was transferred to a higher centre were coronary angiogram facility was available.

Fig: 2 ECG 20 hours after snake bite

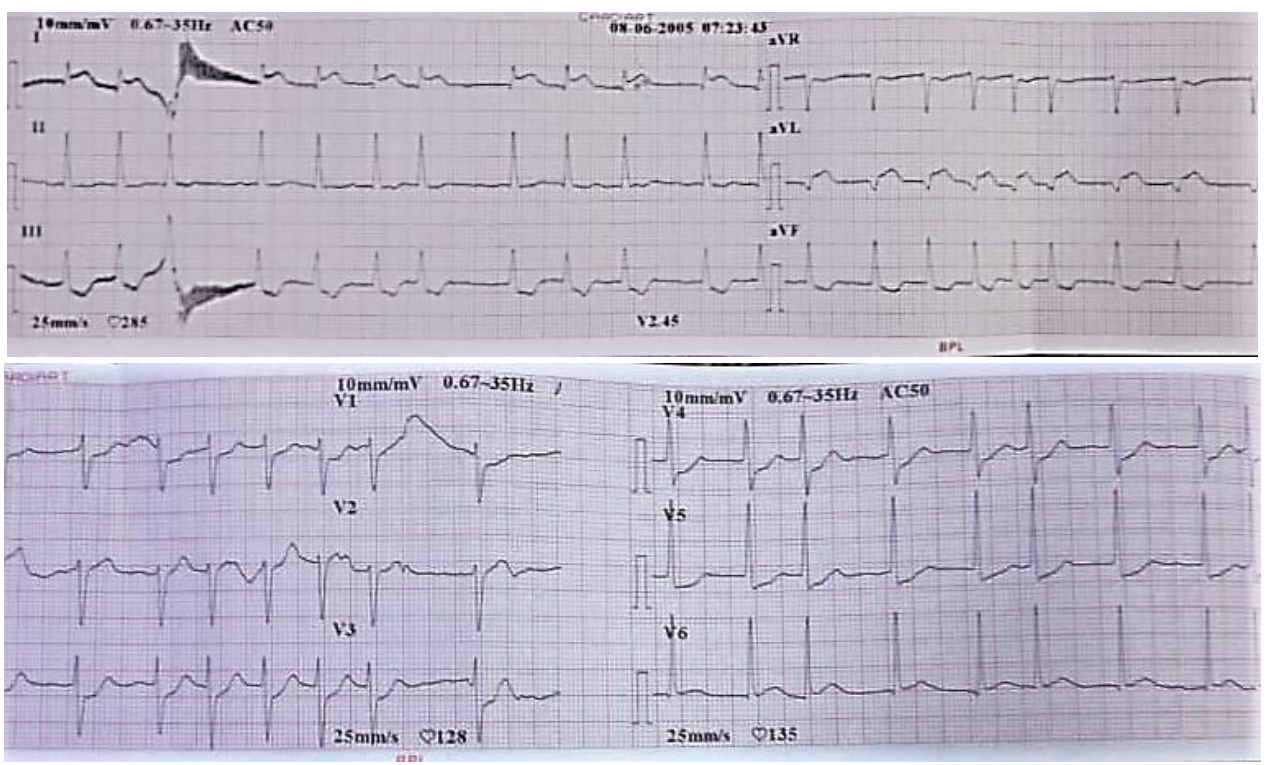


He was managed with anticoagulant, antiplatelet and anti-snake venom. Coronary angiography was done which revealed double vessel disease (60$70 \%$ obstruction in the right coronary artery [RCA] and $70-80 \%$ obstruction in the second obtuse marginal [OM2] segment of left circumflex artery $[\mathrm{LCx}])$. It was probably due to the underlying preexisting atherosclerosis in whom the viper venom led to plaque erosion or rupture leading to STEMI. He was adviced percutaneous coronary intervention (PCI) to RCA and LCx. Repeat ECG after 24 hours showed $\mathrm{HR} \approx 75 / \mathrm{min}$, normal axis, normal sinus rhythm, no significant ST-T changes. Patient symptomatically improved and was hemodynamically stable. As he did not agree for PCI he was discharged and adviced to review on a later date.

\section{Discussion}

Cardiovascular complications are relatively uncommon in snake bite patients when compared to hemotoxicity, neurotoxicity and renal failure. The exact mechanism by which snake bite envenomation causes myocardial ischemia is not clear. However certain mechanisms have been proposed.

- Hypovolemic shock - Haemorrhagins in snake venom increases vascular permeability as part of capillary leak syndrome and cause bleeding tendency. ${ }^{6,7}$

- Hypercoagulability - Procoagulants like arginine ester hydrolase which is present in snake venom can cause hypercoagulability. Haemoconcentration secondary to haemorrhage induced hypovolemia also leads to hyperviscosity and hypercoagulability. All these factors can lead to disseminated intravascular coagulation (DIC). ${ }^{7,9}$

- Dissanayake and sellahewa have described acute myocardial infarction following Russell's viper and proposed a mechanism of predominant coagulant in venom resulting in coronary thrombosis causing myocardial infarction. ${ }^{4}$
- Myocarditis - Direct cardiotoxic effect of snake venom result in myocarditis and extensive myocardial necrosis., ${ }^{2,5}$

- Hoffman et al have reported myocarditis during autopsy in two horses following injection of viper palaestinae venom for the commercial production of antibodies. ${ }^{3}$

- Coronary spasm - Due to endothelins and sarafotoxin which can lead to acute myocardial infarction. ${ }^{6,8}$

- Pramod theetha kariyanna et al did a systematic search of all the reported cases and found that acute myocardial infarction is possible cardiac manifestation following envenomation. $94 \%$ of the cases were post viperidae family envenomation. $25 \%$ of patients had cardiac arrest and the mortality was high at $25 \%{ }^{1}$

- Kounis syndrome - in patients with normal coronary arteries without predisposing factors acute allergic attack following snake bite can induce coronary artery spasm (type 1) or in patients with culprit but quiescent pre-existing atheromatous disease in whom it can induce either coronary artery spasm or plaque erosion or rupture manifesting as acute myocardial infarction (type 2). ${ }^{12}$

\section{Conclusion}

Even though myocardial involvement in Russell's viper snake bite is rare, recording an ECG in all snake bite patients may detect myocardial involvement earlier. If myocardial infarction is suspected after snake bite envenomation, coronary angiography should be considered after hemodynamic stabilization and anti-snake venom therapy.

\section{References}

1. Pramod Theetha Kariyanna, Apoorva Jayarangaiah, Haroon Kamran, Joshua Schechter, Stanley Soroka, Abhimanyu Amarnani, Justina Ray, Mena Yacoub, Michael Post, Sama Al-Bayati, and Samy I McFarlane, Myocardial Infarction after 
Snakebite Envenomation: A Scoping Study Scifed J Cardiol. 2018 ; 2(3):

2. Subburaja T, Gandhi TV, Selvyn JR, Subramaniyan K, Sundaravadivelu V. Russell Viper's Cardiac Bite: A Case Report. Int J Sci Stud 2015; 3(2):237-239.

3. Hoffman A, Levi O, Orgad U, Nyska A. Myocarditis following envenoming with viperaepalaestinae in two horses. Toxicon 1993; 31:1623-8.

4. Dissanayake P, Sellahewa KH. Acute myocardial infarction in a patient with Russell's viper bite. Ceylon Med J 1996; 41:67-8.

5. Silva et al.: Acute Myocardial Infarction following a possible direct intravenous bite of Russell's viper (Daboiarusselli). BMC Research Notes 2012 5:500.

6. Chakrabarti S, Biswas P, Patil S, Pan K. Acute Myocardial Infarction Following Viper Bite: A Rare Scenario. Heart India 2015; 3:18-20.

7. Maheshwari M, Mittal SR. Acute myocardial infarction complicating snake bite. J Assoc Physicians India 2004; 52:63-4.

8. Rafael Alessandro Ferreira Gomes, Fabiano Lima Cantarelli, Franklin Almeida Vieira, Aluisio Roberto Andrade Macedo Jr., Milena Motta de Almeida Gouveia, Audes Diogenes de Magalhães Feitosa Myocardial Infarction after Snake Bite International Journal of Cardiovascular Sciences. 2018; 31(1)79 8.

9. Niraj et al.: Acute myocardial infarction following a Russell's viper bite: a case report. International Archives of Medicine 2013 6:7.

10. WHO/snakebite envenoming /https://www.who.int/snakebites/epidemiol ogy/en/
11. Snake bite- The Association of Physicians of India/ apiindia.org > chapter 94.

12. Nicholas G Kounis, Andreas Mazarakis, Grigorios Tsigkas, Sotiris Giannopoulos\& John Goudevenos; Kounis syndrome: a new twist on an old disease; Future Cardiol.(2011) 7(6), 805-824. 